\title{
RESEARCH
}

\section{Exploring Factors that Influence Student Engagement in Community-Engaged Learning Activities within a Pharmacy Context (ExCEL-Rx)}

\author{
Kayla M Fang, BSc (Pharm), Gilly C Lau, BSc (Pharm), Jamie Y Park, PharmD, Paulo Tchen, MBA
}

The University of British Columbia, Faculty of Pharmaceutical Sciences, Vancouver, BC, Canada

Corresponding Author: Kayla Fang, The University of British Columbia, Faculty of Pharmaceutical Sciences, 2405 Wesbrook Mall, Vancouver, BC, V6T 1Z3. Tel: 604-827-0041. Email: kayla.fang@ubc.ca

Submitted March 12, 2021; accepted August 2, 2021; ePublished August 2021

Objective. To investigate and identify factors that enhance and restrict student engagement in mandatory and voluntary community-engaged learning (CEL) activities.

Methods. A phenomenological study utilizing semi-structured interviews was conducted, exploring students' motivations and barriers faced in their mandatory CEL course and voluntary CEL activities (eg, community outreach). Fifteen students were randomly selected to participate in interviews. Student responses were analyzed using qualitative thematic analysis. Results. Primary factors motivating student engagement in mandatory CEL included having structured learning activities for students and incorporating reflective learning. Motivating factors for students participating in voluntary CEL included personal interest in the topic, convenient location and time of activity, opportunity for career development, and advocating for the pharmacy profession. Overlapping motivations for both mandatory and voluntary CEL included having a better understanding and broader perspective of the diverse populations in the community and imparting a positive impact. Common barriers identified included having limited information about student responsibilities, limited student role, and feeling unconfident or unprepared.

Conclusion. Students perceive benefits from both mandatory and voluntary CEL activities. However, opportunities exist for identifying and managing barriers to enhance student engagement in CEL within a pharmacy program and to further refine the use of learning tools, such as critical reflection, that were identified through this study to have contributed to student engagement with CEL.

Keywords: community-engaged learning, community service learning, student motivation, pharmacy, student engagement

\section{INTRODUCTION}

According to the World Health Organization, mutually beneficial partnerships between communities and educational institutions are essential in achieving social accountability. ${ }^{1,2}$ Many social factors impact an individual's health, such as the social determinants of health, health literacy and availability of education, as well as access to health care..$^{3-7}$ Therefore, in pharmacy education, it is essential that not only are faculties preparing students to fulfill the technical and clinical components of practice, but also as compassionate, ethical, and socially accountable contributing members of society. ${ }^{8}$ In fact, the Accreditation Council for Pharmacy Education (ACPE) has identified a requirement for Doctor of Pharmacy programs across the United States to incorporate a co-curriculum. ${ }^{9}$ Co-curricular activities for students reported by schools of pharmacy in the United States include public health outreach and education events, leadership/professional services, and legislative advocacy, for example. ${ }^{10}$

Similarly, the University of British Columbia's (UBC) Entry-to-Practice (E2P) Doctor of Pharmacy (PharmD) program in Canada has incorporated a mandatory course in community-engaged learning (CEL) in the second year of this four-year program to support students' professional development and to advance learning in the social factors impacting health outcomes, as described above. ${ }^{11}$ In this mandatory CEL course (PHRM 270 Community Service Learning), students are matched with a community partner organization (CPO) to fulfill a minimum of 20 hours of service. Additionally, each student must submit three reflection assignments for successful completion of this course. The CPOs involved and CEL activities completed by students are not necessarily pharmacy or health care related, which provides students the opportunity to focus on the social aspects of the pharmacist's role, such as communication, collaboration, and fostering an empathetic and community-focused perspective and attitude. ${ }^{8}$ For example, some students completed their CEL activities at the Young Women's Christian Association (YWCA) where they participated in early childhood education. Other opportunities at different CPOs included assisting or facilitating English language classes/circles for newcomers to Canada. This exposed students to different perspectives held by the diverse patient demographics they may encounter in their future practice as pharmacists. 
Additionally, many UBC E2P PharmD students are actively involved in voluntary CEL activities, such as community outreach. Community outreach encompasses any extracurricular activity where students elect to provide education to the public on health topics (eg, proper handwashing technique, blood pressure measurement clinics) and/or advocate for the profession of pharmacy while representing themselves as students of the university. Unlike the mandatory CEL course (PHRM 270 Community Service Learning) described previously, these activities are not part of the mandatory program or curricular requirements of the UBC E2P PharmD program. Additionally, the time committed by students for these activities is based on their own personal level of interest and availability to participate. In this type of voluntary CEL, UBC E2P PharmD students are required to first submit a proposal of their activity to the Faculty, and upon the Faculty's approval, students lead the organization, development, and delivery of their activity. Students may be paired with a licensed pharmacist supervisor for their activity when deemed necessary by the Faculty.

Student engagement in CEL activities is important for these experiences to impart the understanding of social accountability. Opportunities for students to be actively engaged in their learning can further enrich their educational experiences and foster their personal and professional growth - characteristics that can be applied throughout their professional careers. ${ }^{12,13}$ Students in UBC's E2P PharmD program are invited to complete standardized course evaluations to provide feedback about their experience in mandatory CEL (PHRM 270 Community Service Learning) at the end of the course. However, these course evaluations focus on topics such as learning objectives, assessments and organization of the course, thereby providing limited insight into motivating and restricting factors for student engagement to the Faculty. Furthermore, while a number of studies exist validating the effectiveness of CEL pedagogy in pharmacy schools, ${ }^{1,14}$ preliminary searches resulted in limited literature investigating student engagement with CEL throughout their pharmacy education. For example, Clark et al. (2015) evaluated a service learning course offered to medical and pharmacy students for the impact on student learning and outcomes. ${ }^{1}$ Results described the experience as being enriching to student development as a health care provider. ${ }^{1}$ To our knowledge, there have not been studies exploring the factors that enhance and restrict student engagement in CEL activities in pharmacy education. Previous studies have explored motivating factors and/or barriers for pharmacy student leadership ${ }^{15,16}$ and professional organization involvement. ${ }^{17}$ For example, Petersen et al. also studied motivating factors for pharmacy students but instead focused on students' decision to join professional organizations, such as the American Pharmacist's Association (APhA), rather than in engagement in CEL activities as in our study. ${ }^{17}$ Therefore, through this study, we aim to investigate and identify motivating factors and barriers to student engagement in mandatory and voluntary CEL activities.

\section{METHODS}

This study employed a phenomenological framework where the phenomenon in question was pharmacy student participation in CEL activities. ${ }^{18}$ In-depth, semi-structured interviews were conducted in October 2019 to gain a deeper understanding of what enhances and restricts pharmacy students' engagement into CEL activities. The interview questions were adapted from similar studies conducted with pharmacy or medical students. ${ }^{17,19,20}$ Ethics approval was obtained from the University of British Columbia's Behavioural Research Ethics Board.

Eligible participants included current UBC pharmacy students in the E2P PharmD program who were enrolled in or had previously taken the PHRM 270 Community Service Learning course (mandatory CEL) in the second year of the program. To recruit participants, an email was sent out to UBC pharmacy students with information about the study, the invitation to participate, and a link to an online survey to provide their contact information for scheduling an interview. Students were also asked to indicate if they had previously participated in community outreach activities (voluntary CEL) in the online survey.

A maximum of 15 interviews were targeted to accommodate the desired timeline of the study. Since more than 15 students expressed interest, the study investigators used random selection to interview up to 8 students indicating in the online survey that they had previously participated in voluntary CEL, with the remaining interviews offered to students who did not previously participate in voluntary CEL.

Before starting each interview, the participants were asked to provide verbal consent to continue with the study and to have their interview audio recorded. The student then participated in a semi-structured interview exploring their involvement in voluntary and mandatory CEL in UBC's E2P PharmD program. Each interview was conducted by phone or in-person by a student investigator to keep the participant's identity confidential from faculty investigators and each interview was audio recorded for accuracy. The student investigator was a year three pharmacy student in UBC's E2P PharmD program who had previously completed mandatory CEL, participated in voluntary CEL activities, and additionally had previous experience in conducting qualitative research. Before conducting the interviews, the student investigator reviewed the research protocol, practiced the interview process with the study investigators and reviewed common pitfalls in interviewing. ${ }^{21,22}$ The student investigator conducted each semi-structured interview utilizing a script with pre-determined questions and suggested follow-up prompts that was co-created together by all four study 
investigators. On average, interviews ranged from 30 to 45 minutes. As an appreciation for participating in this study, all participants received a $\$ 15$ gift card.

After the student investigator transcribed the interviews, participants were offered an opportunity to review the de-identified transcripts of their individual interviews and provide feedback if necessary. They were also able to withdraw their consent to use the collected data at any time. Qualitative thematic analysis was conducted to describe the participants' responses using NVivo 12 (QSR International). The four study investigators reviewed all the transcripts, were involved in line-by-line or segment-by-segment coding, and later constructed themes through an iterative process. The themes were formed based on the frequency of appearance and patterns identified within the dataset and all investigators collaborated to reach a consensus on the final themes.

\section{RESULTS}

In total, 16 pharmacy students expressed interest in participating in the interviews. 15 students ( 5 second year, 10 third year students) met the eligibility criteria and were offered an interview. 13 students (87\%) were younger than 25 years old, 9 students $(60 \%)$ had a degree prior to starting the E2P PharmD program and 9 students $(60 \%)$ had participated in voluntary CEL activities. A total of 240 lines were coded in NVivo 12 (QSR International) with 147 comments identified as motivations and 93 comments as barriers.

\section{Motivating factors}

Motivating factors for student engagement in mandatory and voluntary CEL activities are summarized in Table 1. Motivating factors were determined by the investigators to be the factors that students enjoyed when participating in the activity, that enhanced their engagement in the activity or with community members, were considered by students to be valuable or memorable, and increased their likelihood of participating in the activity again or in similar activities in the future.

For mandatory CEL activities, students expressed that having structured and set expectations, which include having set shifts and being aware of their responsibilities and assignments at their CPO, were motivating factors that enhanced their CEL experiences. As well, students shared the benefits of reflective learning, completed as a requirement for the PHRM 270 Community Service Learning course, which helped "consolidate what [they are] learning and how [they are] growing" (Participant 12).

For voluntary CEL activities, motivating factors included the type of event, which encompassed aspects such as the alignment of topic and type of audience with personal interests and comfort level, flexible or low commitment, and convenient proximity of activity location from home or school. Students also mentioned that being involved in voluntary CEL activities could support their career development because it would allow them to "expand [their] resume and ... [be able to] talk about the experience when [they are] being interviewed for residency/jobs" (Participant 7). Another notable motivating factor for participating in voluntary CEL activities included advocacy for the pharmacy profession. Through voluntary CEL activities, students "want[..] the public to understand the role of pharmacists a little bit better" (Participant 9).

Mandatory and voluntary CEL activities also shared some overlapping motivating factors. Students indicated the opportunity for professional development as a motivating factor, which includes practicing knowledge translation to the public and meeting new students in the E2P PharmD Program. Students shared that "a lot of times the things that we learn, we feel like, it may be insignificant/irrelevant facts, but when you tell a patient, they're grateful for that information and it's [a] rewarding experience" (Participant 3). Students expressed that through these CEL activities, they were able to "get to know someone in pharmacy and [do] something outside of school with them" (Participant 7). Broadened perspectives of the community were another factor that enhanced students' participation. Students learned that "what you think the community understands may not necessarily be what the community understands" (Participant 9). Through their exposure in working with diverse populations, students were able to "improve their cultural competence" (Participant 2) and "tailor or personalize everything [they were] doing for [their] patients based on their situation" (Participant 14). Furthermore, students felt engaged with their CEL experiences when they felt their contributions resulted in a positive impact on the community. For example, a student said that they were able to "[get] in touch with the public and [talk] to them about what [pharmacists] do. [They were able to] see that there was a lot of misunderstandings/myths/assumptions. For example, an opinion that [they] got from the public was "Oh [pharmacists] make drugs" which we don't. It was interesting to talk to public and get to know more" (Participant 9).

\section{Barriers}


The barriers that impacted student engagement in mandatory and voluntary CEL activities are summarized in Table 2. Barriers were determined by the investigators to be factors during a CEL activity that students disliked or did not enjoy, that hindered their participation in the activity, and were viewed as a challenge when participating in the activity.

For mandatory CEL activities, many of the barriers were based on inflexible course components, which included shifts that were dependent on the CPO's schedule but were not always flexible to the student's preferences. Additionally, another barrier identified was not being assigned to a CPO that matched the student's preferences or interests. Students expressed challenges "[setting] specific goals when [they] didn't choose to go into [their designated] organization" (Participant 12). Some students also brought up inconsistencies in learning activities and lack of preparation by their CPOs in comparison with other students. One student shared that often "[their preceptor] wouldn't be too sure with what she had planned for us to do. So, she would just be like, tag along with me and whatever role I'm in, you can help me" (Participant 6). Concern for personal safety was also a barrier shared by students assigned to neighborhoods that they perceived to be less safe. Another barrier identified for engagement in mandatory CEL activities was a lack of psychological resilience. A student shared that some of the life stories told by the community members were difficult to hear as "[they] didn't know what the right way was to respond, and [they] didn't want to say something wrong" (Participant 2). Despite the presence and support of CPO staff, the student mentioned that "[they] took some of these situations home with [them]" (Participant 2).

For voluntary CEL activities, barriers mainly included time constraints, including the time required to commute and attend the CEL activity and the time required for students to create CEL activity content (eg, presentation slides). As well, students indicated that different competing priorities such as academic workload and personal commitments played a role when deciding whether or not to participate in voluntary CEL activities. Particularly for first year students, they mentioned that they "[tried to] get used to [the] workload of pharmacy school instead of looking for community activities" (Participant 3). Furthermore, students were not always aware of the available voluntary CEL activities that they can participate in and this can be a barrier since "sometimes [students] just hear about things right before they happen" (Participant 6).

Overlapping barriers for both mandatory and voluntary CEL activities included lack of confidence and/or feeling unprepared to participate in activities (eg, knowledge gaps in answering questions, being afraid to step outside one's comfort zone, lack of preparatory information on the student's role and responsibilities) (Table 2). In this situation, it can be "daunting to take on a task and you may not necessarily know what you're taking on" (Participant 3). Additionally, in the local jurisdiction, pharmacy students are restricted from providing clinical advice or delivering pharmacy practice activities to the public in the absence of a licensed supervising pharmacist as required by the local pharmacy regulatory body (ie, the College of Pharmacist of British Columbia). ${ }^{23}$ This applies to all mandatory CEL placements (as their assigned supervisors are not licensed pharmacists) and any voluntary CEL activity where a licensed supervising pharmacist is not present. Students identified this restriction to be a barrier for their engagement in activities where there were opportunities to provide clinical advice. For example, students found it frustrating when they could not "tell [the resident] all the evidence behind [the medication] [...] when [they knew] what [the resident was] saying [was] not necessarily true" (Participant 11).

\section{DISCUSSION}

To our knowledge, there is a paucity of data exploring the factors that enhance and restrict student engagement in CEL activities in pharmacy education. In studies exploring pharmacy student leadership ${ }^{15,16}$ and student involvement with professional organizations, ${ }^{17}$ factors that motivated student participation included career development (eg, expanding their resume, networking opportunities), building leadership skills, and making a positive impact in their community. ${ }^{15,16}$ Factors that restricted student involvement included time commitment and location of the CEL event. ${ }^{17}$

Our study provided insight into student engagement in CEL in pharmacy education by looking at student participation in both mandatory and voluntary activities. Several motivating factors and barriers identified in both types of activities were similar to those noted in other studies. ${ }^{24,25}$ For example, time commitment and inconvenient location of events were seen as barriers, whereas opportunities for personal, professional, and career development were seen as motivating factors.

Our results found that students felt more engaged with mandatory CEL activities where there were structured expectations and a defined student role at the CPO. As such, it is reasonable that students also described feeling less engaged where there were mismatched expectations in terms of scheduling and/or their student role. Our findings are consistent with Clark et al. (2015), which reported that the most common barriers for students working with community partners during the community service-learning program were scheduling difficulties and, in some cases, a lack of clarity of the students' roles. ${ }^{1}$ The barriers specific to voluntary CEL activities included challenges in managing logistics and volunteers, which paralleled the phenomenological study conducted by Loh et al. (2015). ${ }^{26}$ Medical students who 
participated in a voluntary community service project shared that they faced obstacles motivating their volunteer committee members, allocating enough time to complete assigned tasks, and implementing new ideas.

Maerten-Rivera et al. recently investigated challenges in implementing the co-curriculum requirement for pharmacy schools in the United States, and identified that a lack of enthusiasm by stakeholders, one of which is the student group, was a commonly reported challenge to successful implementation. ${ }^{27}$ Our study presents motivating factors and barriers for student engagement in mandatory and voluntary CEL activities that may be considered when creating and implementing activities in the co-curriculum. For example, a shared theme between mandatory and voluntary CEL that emerged from this study was the idea that students were more motivated to participate when they felt their contributions would be valued by the community and/or would contribute to their professional development by directly drawing on their pharmacy skills and knowledge of medications and therapeutics. This finding suggests that co-curricular activities that allow for this type of interaction and impact could promote student engagement and enthusiasm in participating in the activity.

Building on the concept of impact to the community, one of the goals of mandatory CEL at UBC's E2P PharmD program is to foster an understanding in students that pharmacy is not strictly focused on medical knowledge, but in actuality, pharmacists also have a role to play in the community to address determinants of health outside of medicationrelated factors. Literature suggests that concepts such as prevention and health promotion are more comprehensive than a purely curative approach focusing on treatments. ${ }^{28}$ Diaz-Cruz asserts that pharmacists, being one of the most accessible health care professionals, are well suited to help minimize health disparities and thus pharmacy education should endeavor to not only expose students to knowledge of health disparities, but also shift their focus from awareness to action and advocacy. ${ }^{29}$ Therefore, further study is merited in exploring methods of reinforcing this point, potentially leveraging reflective learning, which was identified in our study as a tool that enhanced student engagement in CEL activities.

In our program, reflective learning is incorporated into mandatory CEL as a required activity, but not intentionally incorporated into voluntary CEL. In Shulman's table of learning, reflection plays a key role as it builds the ability to exercise judgement in challenging situations where there may be uncertainty or unpredictability. ${ }^{30}$ This judgement leads to commitment which allows for internalization of our understandings, opinions, and values into our identity. ${ }^{30}$ Our results align with this concept, where students identified reflective learning as a factor that enhanced student engagement to "consolidate what [they are] learning and how [they are] growing" (Participant 13). As such, the incorporation of critical reflection in voluntary CEL and refinement of reflection in mandatory CEL within pharmacy education should be considered for future investigation given its importance in fostering personal and professional growth in students.

\section{Limitations}

With phenomenological studies that require participants to recall personal experiences, there is a risk for recall bias. In this case, as there may have been a lag time between the interview and the student's initial CEL experience, recall bias may be present. As well, some students may not have been fully comfortable in sharing their experiences given the involvement of faculty members during data analysis. The study attempted to mitigate this latter concern by ensuring students were aware that their participation in the study would not affect them academically. Moreover, students were advised that a student investigator would independently conduct all interviews with participants and remove all identifiers from the transcribed interviews used for data analysis. We acknowledge this was a single-centred study and the responses shared are not representative of the entire student body given the inherent differences between student backgrounds, genders, and baseline motivation levels. Additionally, only students who had taken part in the mandatory CEL were eligible for our study. As this course was newly implemented in 2018, this limited our sample of students to those from years two and three of this four year program. In following a phenomenological framework and conducting in-depth, semi-structured interviews, we utilized a smaller sample size which produced highly qualitative results, influenced by the study population at the given time. ${ }^{31}$ As a result of this qualitative data, interpretations of this data may be subject to researcher bias, as well. Despite the described limitations, the responses provided were rich and informative and provides opportunities for future research.

\section{CONCLUSIONS}

Students perceive benefits from both mandatory and voluntary CEL activities. Specific motivating factors exist for mandatory and voluntary CEL activities individually, and we found that there were overlapping motivating factors as well. However, there are also barriers that impact student engagement and participation and prevent them from being fully immersed in CEL activities. Opportunities exist for pharmacy educators to address identified barriers for engagement when designing or evaluating CEL activities, to reduce student apprehension in participating in CEL, and to further refine the use of learning tools, such as critical reflection, that were identified through this study to have contributed to student engagement with CEL. 


\section{ACKNOWLEDGEMENTS}

Funding/Support: This study was supported by a grant from the University of British Columbia's Centre for Community Engaged Learning.

\section{REFERENCES}

1. Clark M, McKague M, Ramsden VR, McKay S. Deeper learning through service: evaluation of an interprofessional community service-learning program for pharmacy and medicine students. J Res Interprof Pract Educ. 2015;5(1). doi:10.22230/jripe.2015v5n1a175

2. Boelen C. Towards unity for health: challenges and opportunities for partnership in health development: A working paper. World Health Organization. Published 2000. Accessed November 30, 2020. https://apps.who.int/iris/handle/10665/66566.

3. Marmot M, Wilkinson RG. Social Determinants of Health. $2^{\text {nd }}$ ed. Oxford University Press; 2005.

4. Zhang NJ, Terry A, McHorney CA. Impact of health literacy on medication adherence: a systematic review and meta-analysis. Ann Pharmacother. 2014;48(6):741-751. doi:10.1177/1060028014526562

5. Keller DL, Wright J, Pace HA. Impact of health literacy on health outcomes in ambulatory care patients: a systematic review. Ann Pharmacother. 2008;42(9):1272-1281. doi:10.1345/aph.1L093

6. Aboumatar HJ, Carson KA, Beach MC, Roter DL, Cooper LA. The impact of health literacy on desire for participation in healthcare, medical visit communication, and patient reported outcomes among patients with hypertension. J Gen Intern Med. 2013;28(11):1469-1476. doi:10.1007/s11606-013-2466-5

7. Bindman AB, Grumbach K, Osmond D, et al. Preventable hospitalizations and access to health care. JAMA. 1995;274(4):305-311. doi:10.1001/jama.1995.03530040033037

8. Brown B, Heaton PC, Wall A. A service-learning elective to promote enhanced understanding of civic, cultural, and social issues and health disparities in pharmacy. Am J Pharm Educ. 2007;71(1). doi:10.5688/aj710109

9. Guidance for the accreditation standards and key elements for the professional program in pharmacy leading to the doctor of pharmacy degree. Accreditation Council for Pharmacy Education. https://www.acpeaccredit.org/pdf/GuidanceforStandards2016FINAL.pdf. Published February 2, 2015. Accessed July 9, 2021.

10. Maerten-Rivera JL, Chen AM, Augustine J, et al. Co-curriculum implementation and assessment in accredited doctor of pharmacy programs. Am J Pharm Educ. 2020;84(3):370-380. doi:10.5688/ajpe7569

11. Fang K, Wong G. PHRM 270 Community service learning: student handbook (2019-2020). doi:10.14288/1.0387096. Published 2019.

12. Kuh GD. Assessing what really matters to student learning inside the national survey of student engagement. Change: The Magazine of Higher Learning. 2001;33(3):10-17. doi:10.1080/00091380109601795

13. Kuh GD. What we're learning about student engagement from NSSE: benchmarks for effective educational practices. Change: The Magazine of Higher Learning. 2003;35(2):24-32. doi:10.1080/00091380309604090

14. Kearney KR. Impact of a service-learning course on first-year pharmacy students' learning outcomes. Am J Pharm Educ. 2013;77(2). doi:10.5688/ajpe 77234

15. Moore RJ, Ginsburg DB. A qualitative study of motivating factors for pharmacy student leadership. Am J Pharm Educ. 2017;81(6). doi:10.5688/ajpe816114

16. Phillips JA, McLaughlin MM, Gettig JP, Fajiculay JR, Advincula MR. An analysis of motivation factors for students' pursuit of leadership positions. Am J Pharm Educ. 2015;79(1). doi:10.5688/ajpe79108

17. Petersen E, Wascher M, Kier K. Analysis of pharmacy student motivators and deterrents for professional organization involvement. Curr Pharm Teach Learn. 2017;9(4):543-550. doi:10.1016/j.cpt1.2017.03.024

18. Creswell JW, Poth CN. Qualitative inquiry and research design: Choosing among five approaches. $4^{\text {th }} \mathrm{ed}$. SAGE Publications, Inc.; 2018.

19. Loh AZ, Tan JS, Lee JJ, Koh GC. Voluntary community service in medical school: a qualitative study on student leaders' motivations, experiences, and outcomes. Med Teach. 2016;38(7):683-690. doi:10.3109/0142159X.2016.1150985

20. Saleem F, Hassali MA, Ibrahim ZS, Rasheedy AA, Aljadhey H. Perceptions and attitudes of pharmacy students towards volunteering at health promotional programs: a cross-sectional study from Malaysia. J Community Health. 2015;40(2):285-290. doi:10.1007/s10900-014-9930-y

21. Pope C, Mays N. Qualitative Research in Health Care. $3^{\text {rd }}$ ed. Oxford: Blackwell Publishing; 2006.

22. Morse JM, Field PA. Nursing Research: The Application of Qualitative Approaches. $2^{\text {nd }}$ ed. Boston, MA: Springer; 1996. 
23. Health professions act: Bylaws. College of Pharmacists of BC. http://library.bcpharmacists.org/6_Resources/61_Provincial_Legislation/5076-HPA_Bylaws.pdf. Published March 15 2021. Accessed July 9, 2021.

24. Barner JC. First-year pharmacy students' perceptions of their service- learning experience. Am J Pharm Educ. 2000;64:266-271.

25. Byers LG, Gray K. The meaning of service learning in an MSW course. J Teach Soc Work. 2012;32(3):257-267. doi:10.1080/08841233.2012.688095

26. Loh AZ, Tan JS, Lee JJ, Koh GC. Voluntary community service in medical school: a qualitative study on obstacles faced by student leaders and potential solutions. Glob Health Action. 2015;8(1). doi:10.3402/gha.v8.27562

27. Maerten-Rivera JL, Chen AM, Augustine J, et al. Challenges to implementation of the co-curriculum in accredited pharmacy programs. Am J Pharm Educ. 2021;85(5):345-354. doi:10.5688/ajpe8301

28. Satcher D, Higginbotham EJ. The public health approach to eliminating disparities in health. Am J Public Health. 2008;98(3):400-403. doi:10.2105/AJPH.2007.123919

29. Diaz-Cruz ES. If cultural sensitivity is not enough to reduce health disparities, what will pharmacy education do next? Curr Pharm Teach Learn. 2019;11(5):538-540. doi:10.1016/j.cptl.2019.02.003

30. Shulman LS. Making differences: A table of learning. Change: The Magazine of Higher Learning. 2002;34(6):36-44. doi:10.1080/00091380209605567

31. Webb A, Welsh AJ. Phenomenology as a methodology for scholarship of teaching and learning research. Teaching \& Learning Inquiry: The ISSOTL Journal. 2019;7(1):168-181. doi:10.20343/teachlearninqu.7.1.11 
Table 1. Motivating Factors that Enhance Student Engagement in Mandatory and Voluntary Community-Engaged Learning Activities

\begin{tabular}{|c|c|c|}
\hline Type of CEL Activity & Theme & Quotes \\
\hline \multirow[t]{2}{*}{ Mandatory } & $\begin{array}{l}\text { Structured and } \\
\text { Set Expectations }\end{array}$ & $\begin{array}{l}\text { "More organized and certain amount of time committing... You know what the expectations are going to be." } \\
\text { (Participant 15) }\end{array}$ \\
\hline & Reflective Learning & $\begin{array}{l}\text { "I personally like reflections. I know a lot of students don't. It just helps me really consolidate what I'm learning and how } \\
\text { I'm growing. I think that's a nice part about [mandatory CEL activities] that we don't necessarily get with therapeutic } \\
\text { courses." (Participant 13) }\end{array}$ \\
\hline \multirow[t]{4}{*}{ Voluntary } & Type of Event & "How often you have to go, commitment (eg, training/how long event is/who is running/where)" (Participant 2)〉 \\
\hline & Career Development & $\begin{array}{l}\text { "I think they believe it can help reach their goal in the end. If they want to do something, gain a position later that will } \\
\text { look good on their resume,that could be a good motivational factor." (Participant 4) }\end{array}$ \\
\hline & $\begin{array}{l}\text { Advocacy for Pharmacy } \\
\text { Profession }\end{array}$ & "I wanted the public to understand the role of pharmacists a little bit better." (Participant 9) \\
\hline & & "I found it fun to advocate for our profession. Help make a difference." (Participant 7) \\
\hline \multirow[t]{5}{*}{ Mandatory \& Voluntary } & $\begin{array}{l}\text { Professional } \\
\text { Development }\end{array}$ & $\begin{array}{l}\text { "I found it interesting to learn about this topic. I did this presentation in } 1 \text { st year before I learned about the } \\
\text { [cardiovascular] module. I enjoyed learning from upper years about clinical pearls and also practicing explaining those } \\
\text { ideas to the general public." (Participant 4) }\end{array}$ \\
\hline & Broadened Perspectives & $\begin{array}{l}\text { "There are just some things that you need to go outside and confront head on. You quite quickly notice that not everyone } \\
\text { has the same opportunities as you. That's a key feature about volunteering for me." (Participant 5) }\end{array}$ \\
\hline & & $\begin{array}{l}\text { "The priorities are different for those who don't have a home or have a stable life. It does help a lot to see what's most } \\
\text { important to the patient. [...] CSL really helped me better understand the needs of other people. What their barriers are } \\
\text { and how to overcome them." (Participant 14) }\end{array}$ \\
\hline & $\begin{array}{l}\text { Making a Positive } \\
\text { Impact on the } \\
\text { Community }\end{array}$ & $\begin{array}{l}\text { "It's a Chinese senior outreach community. I also speak Mandarin. A lot of the Chinese seniors spoke Mandarin, so there } \\
\text { was a cultural connection. Also, I have } 2 \text { grandparents living here who participate in these events. So, when I helped } \\
\text { these Chinese seniors, it was a self-fulfillment kind of feeling because I'm helping people like my grandparents." } \\
\text { (Participant 15) }\end{array}$ \\
\hline & & $\begin{array}{l}\text { "These are people had a bad experience with health professionals. It was nice for them to see that we're there and we } \\
\text { know what their situation is and what they do for survival. We're not judgmental. For them to see that we're just } \\
\text { interacting with them and are at the same level as them. They would always tell us how much they appreciate us helping } \\
\text { out. I think it was a very rewarding experience" (Participant 14) }\end{array}$ \\
\hline
\end{tabular}


Table 2. Barriers that Restrict Student Engagement in Mandatory and Voluntary Community-Engaged Learning Activities

\begin{tabular}{|c|c|c|}
\hline Type of CEL Activity & Theme & Quotes \\
\hline \multirow[t]{4}{*}{ Mandatory } & $\begin{array}{l}\text { Inflexible Course } \\
\text { Components }\end{array}$ & $\begin{array}{l}\text { "I know it's hard to say but having more flexibility. Even if you have to miss a session, being able to make up for it } \\
\text { in a week. If you have an exam that week, it may be hard for someone to go dedicate their time and travel time as } \\
\text { well." (Participant 11) }\end{array}$ \\
\hline & & $\begin{array}{l}\text { "But definitively, some people didn't get their first choice and so the passion wasn't there. If there were more buffer } \\
\text { room so people could get their first choices. That would make it better." (Participant 7) }\end{array}$ \\
\hline & $\begin{array}{l}\text { Inconsistent Learning } \\
\text { Targets and Activities }\end{array}$ & $\begin{array}{l}\text { "Maybe having more set schedule for the students. So, students know what to expect. There are other community } \\
\text { placement sites, where students have a more flexible role. But then, if it is defined, then students would know what } \\
\text { to expect on their shift. For us, it was undefined." (Participant 10) }\end{array}$ \\
\hline & Student Safety & $\begin{array}{l}\text { "Also, being in that area. It's not the best area. [...] Fear of going around there. It was just me in that practicum." } \\
\text { (Participant 13) }\end{array}$ \\
\hline \multirow[t]{3}{*}{ Voluntary } & Time Constraints & $\begin{array}{l}\text { "When I was doing Rho-Chi presentation, we basically pulled up [Compendium of Therapeutic Choices] and } \\
\text { [hypertension] guidelines to put together a presentation. I expected there to be resources there to support and I } \\
\text { would just be there to talk. Whereas, some of the other outreaches (eg, hand hygiene), there would be a kit and } \\
\text { supplies." (Participant 5) }\end{array}$ \\
\hline & & $\begin{array}{l}\text { "The time it takes for someone to lead something (eg, background gathering, contacting schools, previous execs, } \\
\text { organizing, making a committee for it), it's time-consuming for sure." (Participant 7) }\end{array}$ \\
\hline & Different Priorities & $\begin{array}{l}\text { "We have to be able to balance our academic and our extracurricular time very well. If I feel like I don't have } \\
\text { enough time to attend an event because I have a test the next day, then I would not commit myself to the event." } \\
\text { (Participant 9) }\end{array}$ \\
\hline \multirow[t]{3}{*}{ Mandatory \& Voluntary } & $\begin{array}{l}\text { Lack of Preparatory } \\
\text { Information on Student } \\
\text { Role }\end{array}$ & $\begin{array}{l}\text { "I am happy to volunteer but there was lack of information about the activities and knowing whether I qualified to } \\
\text { help out." (Participant 6) }\end{array}$ \\
\hline & $\begin{array}{l}\text { Lack of } \\
\text { Confidence/Readiness }\end{array}$ & $\begin{array}{l}\text { "Challenge could be you are asked to answer a question that may be more challenging or going to areas that we } \\
\text { may not have covered. That's additional research work you may have to put in." (Participant 2) }\end{array}$ \\
\hline & & "Fear of putting yourself out there. Fear of reaction of the public/audience." (Participant 7) \\
\hline
\end{tabular}

